\title{
Revolution Against Non-violent Oppression
}

\section{Zsolt Kapelner ${ }^{1,2}$ (D)}

Published online: 23 July 2019

(c) The Author(s) 2019

\begin{abstract}
Oppressive governments that use violence against citizens, e.g. murder and torture, are usually thought of as liable to armed revolutionary attack by the oppressed population. But oppression may be non-violent. A government may greatly restrict political rights and personal autonomy by using surveillance, propaganda, manipulation, strategic detention and similar techniques without ever resorting to overt violence. Can such regimes be liable to revolutionary attack? A widespread view is that the answer is 'no'. On this view, unless a government is or is likely to turn violent, revolution against it is disproportional. After all, revolution would involve launching potentially lethal attacks against oppressors who do not threaten the lives and bodily integrity of their subjects but pose only lesser threats. I argue that this claim of disproportionality is false. Armed revolution against Stably Non-violent Oppressive Regimes (which are neither violent, nor are likely to become violent) can be proportional under some circumstances, thus they may be liable to revolutionary attack. My argument relies on the Responsibility-Sensitive Account of Proportionality. This account holds that responsibility for posing threats renders agents liable to greater defensive harms than the harms with which they threaten. Even if non-violent oppressive regimes do not threaten citizens with murder, serious physical injury, or enslavement, their responsibility for creating an environment in which citizens' political rights and personal autonomy are extremely restricted may loosen the proportionality requirement of inflicting defensive harm and render them liable to revolutionary attack.
\end{abstract}

Oppression comes in many shapes and sizes. States that subject their citizens to violent oppression, e.g. torture, murder and enslavement, commit an especially grave moral wrong, and are usually regarded as liable to armed revolutionary attack by the oppressed citizens. But what if a state uses non-violent, yet still oppressive means to restrict citizens' ability to exercise their rights and lead autonomous lives-e.g.

Zsolt Kapelner

kapelner_zsolt@phd.ceu.edu; kapelner.zsolt@gmail.com

1 Central European University, Budapest, Hungary

2 Budapest, Hungary 
surveillance, propaganda, manipulation, strategic detention-while blocking all routes to peaceful regime change? Many authors have argued that armed revolution as a response to non-violent oppression is always disproportional. I argue that this is false. In some cases, revolution against non-violent oppression is proportional. In such cases citizens subject to non-violent oppression do not have to acquiesce in their situation; they can rise up in arms to defend their rights, for non-violent oppressors, in these cases, are liable to revolutionary attack.

\section{Revolution as Defence Against Oppression}

Revolutions are extremely complex historical and political phenomena whose philosophical evaluation may be approached from a number of different angles (Smith 2008; Buchanan 2013, 2016; Parry 2018). Here I focus on a particular type of revolution which raises specific moral challenges, i.e. armed revolutions involving lethal force. An intuitive way to understand these events is to treat them as defensive wars by citizens against their oppressors. ${ }^{1}$ In this paper I follow this approach. I adopt a broadly reductionist view of morality in war, that is, I take it that moral considerations about using lethal force in war, including revolutions, is derivative upon the ordinary morality of inflicting defensive harm (McMahan 2009; Finlay 2015). ${ }^{2}$

Revolution, so understood, raises many problems. I will focus on the question of liability to revolutionary attack. I ask under what conditions are oppressors liable to potentially lethal defensive harm by citizens as a response to oppression. I take individuals to be liable to harm when they forfeit their right against being harmed, thus harming them is not wrongful (Frowe 2014, p. 73; see McMahan 2009, p. 10). It is important to distinguish the question of the liability of oppressors to revolutionary attack from the overall justifiability of revolution. The overall justifiability of revolution depends on whether revolutionaries have a just cause, a reasonable chance of success, whether they avoid disproportionately burdening or harming non-revolutionary citizens and others, and a great many other criteria (Buchanan 2013, p. 296). Discussing all these criteria is beyond the scope of this paper. Here I discuss only the question of the liability of oppressors to revolutionary attack. Liability is neither a necessary, nor a sufficient condition for the justification of revolution. Inflicting lethal harms on non-liable individuals can be justified, e.g. as a matter of choosing the lesser evil, that is, to avoid even greater harms and injustices. Liability is also insufficient for a justified attack. Even if oppressors are not wronged if killed, counterweighing considerations, e.g. excessive expected harms on the part of non-combatant citizens, may advise against the revolution. Still, liability to be killed makes it easier to justify revolution, for it removes one important objection to it, that is,

\footnotetext{
1 John Locke famously discusses revolution in these terms (Locke 1982, p. 135). Most authors cited above take a similar stance.

${ }^{2}$ Of course, this is not the only possible approach to the problem at hand. Mattias Iser (2017) provides an insightful critique of applying reductionism to the problem of revolutions.
} 
oppressors' right not to be killed or put in lethal danger. This is especially relevant in case of the specific type of oppression under discussion in this paper.

Some oppressors clearly are liable to necessary and proportional defensive harm which may involve revolutionary attack. ${ }^{3}$ These are, for example, regimes that Allen Buchanan calls Resolute Severe Tyrannies and which I call Violent Oppressive Regimes. A regime falls into this category if it "persistently violates some of the basic human rights of large segments of the population, is extremely authoritarian (that is, wholly undemocratic), and is utterly impervious to efforts to reform it' (Buchanan 2013, p. 296). Such regimes regularly engage in the murder, torture, unjust imprisonment and enslavement of their own citizens, and therefore are liable to potentially lethal revolutionary attack aimed at averting these threats.

But oppression may take shape in other, more insidious ways. Governments may refrain from murder, torture and similar atrocities while systematically depriving their citizens from the ability to exercise a wide range of fundamentally important rights. They may create regulatory conditions under which the independent media is unable to function. They may build a legal environment in which civil society organizations are unable to finance themselves, in which political parties are incredibly hard to register and to operate. They may use propaganda campaigns and manipulation to deter people from exercising their rights. They may implement widespread surveillance to force citizens to police and censor themselves without actually using force against anyone. They may non-violently, yet persistently harass dissenters, or use short-term detention against them; whenever a protest is planned, its organizers are briefly detained, maybe only for a few hours, just long enough to make them unable to carry on with their dissident activity. Dissenters may face other kinds of hardships as well, for example, they may be publicly shamed in the media, their employers may be pressured into firing them through fines and inspections.

None of these techniques involve anything we would recognize as violence or severe tyranny in Buchanan's sense. Citizens of such regimes do not have to fear murder, torture or unjust life sentences, but they are unable to exercise an extensive array of their rights and to live their lives as free citizens of a free state. Are such Non-violent Oppressive Regimes ever liable to revolutionary attack? A widespread answer is 'no'; we should resist the idea that there is 'a general and undifferentiated right to kill in defence of one's liberty’ (Norman 1995, p. 128; see Rodin 2002, p. 48 ), that is, as defence against any sort of oppression. In other words, the mere fact of oppression is insufficient for establishing liability to be killed.

To clarify, let me introduce the notion of vital and non-vital interests (Lazar 2014, pp. 14-15; Rodin 2014, p. 81; see Frowe 2014, Chapter 5.1.2). Vital interests include interests in not being murdered, tortured, raped, seriously wounded or enslaved; setting back these interests constitutes an extreme, perhaps the most extreme, injury to one's dignity and standing as a human being. Non-vital interests encompass all other interests, e.g. our interest in having breakfast, finding love and exercising our political rights. Violent oppression seems to be an offence against our vital interests.

\footnotetext{
3 For a detailed discussion on the necessary and sufficient conditions of liability to defensive harm see McMahan (2009, Chapter 4.2), Quong (2012) and Frowe (2014, Chapter 3).
} 
Non-violent oppression, on the other hand, seems to concern only non-vital interests. It is vitally important for us not to be subjected to the type of violence Violent Oppressive Regimes usually use against citizens. Not being oppressed per se, while being extremely important, is not nearly as vitally important an interest as not being murdered, tortured, enslaved and so on.

Thus, taking up arms against non-violent oppressors would mean threatening their vital interests, e.g. in not being killed, as a response to threats to our non-vital interests in not being oppressed. Such a response would therefore violate the proportionality requirement. ${ }^{4}$ To put it simply, non-violent oppression does not appear to be a serious enough matter to render its perpetrators liable to be killed. Other types of arguments, e.g. lesser evil arguments, for revolution against Non-violent Oppressive Regimes are even more demanding. Liable oppressors have forfeited their right against being killed. Thus, in considering the overall justifiability of revolution, the wrong of them being killed can be discounted. In the absence of liability, therefore, the overall reasons for revolution need to outweigh not only the harms that befall on non-combatant citizens, and other externalities, but also the wrong of killing oppressors.

I agree that our interest in not being non-violently oppressed is not a vital interest. Being exposed to propaganda and extensive surveillance or not being able to exercise free speech is not the same type of wrong as having to live in constant fear of murder, torture, and enslavement. Still, non-violent oppression may be extremely severe. It prevents individuals from leading autonomous lives in full enjoyment of their rights. It deprives individuals from the opportunity to pursue projects crucially important for them as citizens and human beings. Even if subjects of non-violent oppression live a minimally dignified life, free from immediate physical threats and serious material deprivation, they are deliberately prevented from engaging in a range of activities that are necessary to live as free and equal citizens in human society. Is it true that if all routes to peaceful regime change are blocked, such people must acquiesce in their situation and should not to try to break free by using revolutionary force? I believe the answer is 'no'.

Christopher Finlay offers a way out for the non-violently oppressed (Finlay 2015, p. 85). He argues that if non-violent oppression is likely enough to turn violent, then citizens may not be required to wait until the murder and torture begin, but rather may decide to escalate the situation and initiate a revolutionary attack. That is, a high enough probability of becoming violent may render even non-violent oppressors liable to revolutionary attack. But as Finlay remarks, 'this way of looking at oppressive states relies on empirical expectations that are unlikely to be true in many cases' (Finlay 2015, p. 85). Indeed, there is no a priori reason to believe that a nonviolent regime will eventually turn violent; a Stably Non-violent Oppressive Regime that never has to turn to physical force is very much conceivable.

\footnotetext{
${ }^{4}$ To be more precise, it violates the requirement of narrow proportionality, i.e. the proportionality of the magnitude of defensive harm compared to the magnitude of threatened harm (McMahan 2009, pp. 20-21). In this paper I focus only on narrow proportionality and set aside the issue of wide proportionality, which concerns the harms inflicted on third parties, e.g. non-revolutionary citizens.
} 
One may doubt if there is any use to contemplating such possibilities. Authoritarian regimes do use non-violent techniques, e.g. oppressive legislation in Russia (Pitts and Ovsuannikova 2015), or censorship in China (Chen and Xu 2017), but these are almost always coupled with more violent forms of oppression. Today, severe oppression is seldom exclusively, let alone stably non-violent. Still, many authors emphasize the increasing prevalence of non-violent oppression (Varol 2015; Guriev and Treisman 2018), and as technological development and expertise make these techniques more refined and efficient, they may very well become preferable to costly violent repression. Think of the tremendous possibilities for surveillance and control that lie in China's evolving social credit system. For these reasons Stably Non-violent Oppressive Regimes are very much worth discussing.

The possibility of Stably Non-violent Oppressive Regimes poses a specific problem. If oppressors can always rely on manipulation, strategic detention and other non-violent techniques, there is no need for them to uphold a lingering threat of open physical violence in any meaningful sense. Finlay's argument therefore provides no guidance as to how to counter Stably Non-violent Oppressive Regimes. His advice would be to keep engaging in non-violent resistance until a threat of violent repression emerges. Only then may the people rise up in arms. But if the regime is indeed stably non-violent, then this threat never emerges. And if all routes to peaceful regime change are blocked, then non-violent resistance is bound to be futile. This argument, in effect, concedes that victims of these forms of oppression have no choice but to stay put and suffer their lot, and perhaps hope for the opportunity of meaningful non-violent resistance to arise, if it ever does. I believe, however, that this conclusion is untenable.

\section{The Abusive Boyfriend}

Before moving on to the main argument, let me first introduce a scenario which does not relate directly to the topic of revolution, but which will be very instructive later on:

The Abusive Boyfriend Scenario 1: A woman called Abigail has an abusive boyfriend, Bob. Bob does not subject Abigail to physical abuse, rape or torture, but she is not free to lead her life any way she likes either. She cannot meet whomever she wants, work wherever she wants, read whatever she wants and so on. Bob achieves this through non-violent means. For example, he does not give her a key to their apartment or their car. She is always free to leave, but she risks being locked out if she stays out too long. She always needs to ask him to drive her, which he sometimes refuses. He protects various communication channels and bank accounts with passwords he sometimes shares, but often changes. He uses manipulation, shaming and other psychological techniques to keep her at bay, but he never threatens with physical violence. He also non-violently blocks all escape routes, manipulates her friends and family so that they refuse to help her, utilizes his social status to discredit her in front of authorities, etc. If she tried simply to walk off, she would find herself 
without access to money, means of transportation and a place to stay; friends, family and authorities under the manipulative influence of Bob would advise her to return to him, and she-herself not immune to his persuasive personality - would most likely decide that she does not have better options anyway.

Abigail is not imprisoned, enslaved or impoverished in any straightforward sense of the term. She is not brainwashed or otherwise mentally incapacitated-although she is exposed to psychological pressure and manipulation. Nevertheless, she enjoys considerable freedom of movement and bodily integrity, she has access to the resources for her own use, and compared with those living in far more abusive relationships - characterized by physical domestic abuse, marital rape and so on-she might be thought to live a relatively dignified, or at least bearable life. It seems safe to say that only Abigail's non-vital interests are set back by Bob.

Still, in her life choices, from the most mundane ones to the most serious ones concerning career and personal relationships, she is always constrained by Bob, however non-violently. She is always at his mercy, not because she needs to fear physical retribution or verbal aggression, but because he controls the resources that she needs for acting on her choices. Were she to decide to act against his wishes, she would quickly find herself unable to do so. He would change passwords, lock away car keys, convince friends to talk her out of carrying out her plans and so on; that is, he would non-violently pressure her into refraining from action. She can only carry out her projects due to his goodwill, which he is always free to withdraw, and this is true of almost all areas of her life.

Suppose that the only way for Abigail to end her abuse is to kill Bob. Is Bob liable to be killed? The intuitive answer is 'yes'. There appears to be a strong intuition according to which Abigail does not have to acquiesce in her situation but may proceed to kill Bob without wronging him, thereby freeing herself. Bob does not seem to have grounds for legitimate complaint against Abigail's lethal response to his actions, for by engaging in his very extensive oppressive practices he seems to have forfeited his rights to such complaints. It seems strange to say that Bob can render Abigail morally required to stay put and submit to abuse by limiting himself to threatening only her non-vital interests. After all, an extensive array of her fundamental, though non-vital, interests are being set back and it seems that no amount of self-restraint can absolve Bob from suffering whatever harm may befall on him as a consequence of Abigail's pursuit of a life free from abuse.

Thus, Bob seems to be liable to be killed even though he does not set back any of Abigail's vital interests. What explains this? One answer is that Bob dominates Abigail, i.e. he deprives her from her autonomy or independence, and this is what explains his liability to be killed. This explanation is insufficient. Some forms of domination, e.g. enslavement, do make people liable to be killed, others do not. Despotic parents and bosses often dominate others but are not always liable to be killed. The question is precisely what it is about the specific type of domination in which Bob engages that makes him liable to be killed. How can domination without setting back vital interests be sufficient for forfeiting one's right not to be killed?

A possible explanation could be Helen Frowe's Aggregation Account (Frowe 2014, p. 140 ff.). On her view, while no threat to an individual non-vital interest 
may warrant lethal defence, the various threats Bob poses aggregate. To use Frowe's example: if someone breaks my arm, I may not respond with lethal defensive force. The interest set back is simply not important enough. But if someone repeatedly breaks my arm thus rendering me unable to use my arm, the threat, still non-vital, may be grave enough to warrant a lethal response. Similarly, Bob's threats to Abigail's non-vital interests jointly render him liable to be killed in self-defence, even though at no point does he pose any threat to Abigail's vital interests.

This explanation is also incomplete. Bob's extensive setbacks to Abigail's nonvital interests are not morally equivalent with threats to her vital interests, as Frowe's account would imply. To see why, consider the following modified scenario:

The Abusive Boyfriend Scenario 2: Bob has two abused girlfriends, Abigail and Caroline. Both are subjected to the same kinds of restrictions. However, Caroline is made instrumental by Bob in Abigail's abuse. For example, he non-violently coerces her to handle Abigail's access to passwords and communication channels, he makes her spy and report on Abigail, he manipulates her into partaking in Abigail's psychological abuse. All the while Caroline acts under Bob's non-violent coercion and is perhaps also manipulated into believing that this is for Abigail's own good. Bob becomes extremely reliant on Caroline, so much so that he ceases to be capable of carrying out his oppressive practices without her.

In this scenario, again, none of the abused girlfriends are exactly enslaved. For example, Caroline is not threatened with physical force or deprivation if she refuses her tasks. In principle, she is free to pursue other jobs, but when she has a job interview, he is not available to drive her. Whenever she looks up job ads, he decides to withdraw the Wi-Fi password for a few days. Using his manipulative techniques, he presents helping with Abigail's non-violent oppression as a form of charity towards a friend who needs help and guidance, and refusing helping Abigail as a form of extreme selfishness, so that Caroline cannot help feeling that she should prioritize these tasks over her own projects; and even when she is not entirely convinced, she has no options to act otherwise due to her own non-violent oppression by Bob.

Suppose that Abigail's only way to free herself in this scenario is to kill Caroline. Is Abigail in any way justified in killing her? In my view, the answer is 'no'. Caroline is not complicit in the oppression. She acts under non-violent coercion and is as much a victim of Bob as Abigail. There is absolutely no reason why Caroline's misfortune of being not only oppressed by Bob, but also being made to contribute to the oppression of a fellow victim would establish that in addition to her torment by Bob, she should also suffer the harm of being killed for Abigail's sake.

This refutes the claim that Frowe's Aggregation Account sufficiently explains Bob's liability to be killed. On the Aggregation Account Bob is liable to be killed because he sets back such an extensive array of Abigail's non-vital interests that his threat becomes equivalent with a threat to her vital interests. But Caroline poses the same kind of threat to Abigail's interests as Bob does. Thus, according to the Aggregation Account, she is liable to the same kind of defensive harms as Bob is. But this is intuitively false. Caroline is not on a par with Bob in terms of liability. It might be the case that Caroline is liable to some defensive harm, or at least some harm can 
be permissibly inflicted on her. But killing seems to be disproportionate. Caroline is non-violently coerced into threatening Abigail's non-vital interests. Intuitively, she does nothing by virtue of which she would forfeit her right not to be killed. She poses an innocent threat to Abigail's non-vital interests.

Note that if Caroline innocently threatened Abigail's vital interests, e.g. if she were coerced into killing her, the situation would be different. It is permissible to defensively kill innocent agents who threaten our vital interests (Thomson 1991, p. 287; Quong 2009, p. 530; see also Otsuka 1994; Frowe 2014, Chapter 2). But Caroline is not such a threat. She innocently threatens Abigail with non-violent abuse; as a consequence, she might have to bear some burdens for Abigail's sake, but there is no reason why she would be required to bear the burden of being killed for her freedom. The Aggregation Account cannot explain why this is the case. On this account Caroline's threats, similar to those of Bob, should aggregate rendering Abigail justified in killing her fellow victim to free herself. This result is extremely counterintuitive. Abigail is not justified in any way in killing Caroline. Therefore, the explanation of Bob's liability cannot be that his aggregated threats to Abigail's non-vital interests count as a threat to her vital interests, as the Aggregation Account claims.

The Aggregation Account is not false. It is worse to threaten a wide array of nonvital interest than just a few. But the example of Caroline shows that this insight is insufficient to establish that in the Abusive Boyfriend Scenario the threats to an extensive enough array of Abigail's non-vital interests warrant threatening Bob's vital interests as a defensive response. If it did, Abigail could permissibly kill Caroline too, but this is intuitively false. Of course, this intuition may prove to be theoretically untenable upon further reflection. However, in my view, it is strong enough to raise doubts about the Aggregation Account's ability to provide a sufficient explanation for Bob's liability. If we can find another principle that convincingly explains why Bob is liable to be killed, but Caroline may not be permissibly killed, we have good reasons to accept it. This, in turn, will prove to be very instructive when it comes to Stably Non-violent Oppressive Regimes.

\section{Proportionality and Responsibility}

In the Abusive Boyfriend Scenario Bob is liable to be killed, but Caroline is not. Intuitively, while some harm may be inflicted on Caroline, killing her would be disproportionate. What kind of principle of proportionality is at work here? In my view, what best explains why Bob is liable to be killed, but Caroline should be left alive is the Responsibility-Sensitive Account of Proportionality. This account holds that proportionality in case of defensive harm is sensitive to the degree of responsibility on the part of threatening agents. The more responsible one is, the less strict the proportionality requirement becomes. As Kai Draper writes:

The less responsible the aggressor and the more responsible his potential victim, the weaker the consideration of justice that counts in favour of permitting harming the aggressor to prevent the infringement of the potential victim's 
rights, and hence the easier it is for that consideration to be overridden by considerations of well-being. (Draper 2009, p. 81)

In other words, greater responsibility loosens the proportionality requirement: defence against agents who are responsible for posing a threat may involve greater harms than the harms with which the responsible agent threatens. For example, if one deliberately poses a threat of wrongful and painful pinching, call this person the Annoying Pincher, one might think that responding by inflicting greater harms than pinching, e.g. pushing or punching, is justified, although killing or torture are not. In contrast, someone who is addicted to pinching, call her the Addicted Pincher, and as such is much less responsible for posing a threat, may not be subjected to harms greater than pinching itself.

Responsibility is a notoriously complex and contested notion. Here I simply take responsibility to mean what Seth Lazar calls agent responsibility: 'where one is agent-responsible for doing $x$ if one voluntarily chose to $x$, and, when choosing, one met the (appropriately specified) minimum standards of responsible agency' (Lazar 2009, p. 702). These minimum standards of agency include various cognitive and epistemic conditions, as well as sufficient control over the consequences of what one does. Agent responsibility should be distinguished from richer and more demanding notions, such as moral responsibility and culpability which concern the appropriate attribution of praise or blame for one's actions.

One might worry that the Responsibility-Sensitive Account of Proportionality is in fact the Responsibility Account of Liability in disguise. This latter view, defended, for example, by McMahan, holds that 'the criterion of liability to defensive killing is moral responsibility, through action that lacks objective justification, for a threat of unjust harm to others' (McMahan 2005, p. 394). Furthermore, the 'Responsibility Account treats liability as a matter of degree. Responsibility for an unjust threat can vary in degree, and liability varies concomitantly' (McMahan 2005 , p. 395). Is this not the same as the Responsibility-Sensitive Account of Proportionality? For example, to say that the Addicted Pincher is liable to lesser harms than the Annoying Pincher seems to be the same as to say that the Addicted Pincher is less liable to harms than the Annoying Pincher.

However, even if the Responsibility-Sensitive Account of Proportionality tends to produce similar results to the Responsibility Account of Liability, the two are not equivalent, and nor does the Responsibility-Sensitive Account of Proportionality presuppose a Responsibility Account of Liability. First, the two are not equivalent because the scope of the Responsibility-Sensitive Account of Proportionality is wider than that of the Responsibility Account of Liability. The former accounts for cases of non-liable threats as well as liable ones. For example, it implies (correctly) that in the case of non-liable lethal threats defensive killing is proportional. Second, the Responsibility-Sensitive Account of Proportionality does not presuppose the Responsibility Account of Liability, for it is compatible with

\footnotetext{
5 The principle is also stated in McMahan (1994, p. 265, 2005, p. 400, 2009, p. 175), Lazar (2014, p. 17). See also Frowe (2014, pp. 173-177) and Quong 2015). I standardized spelling in the quote.
} 
responsibility-insensitive theories of liability. Take, for example, a Causal Account of Liability which holds that agents causally involved in posing threats are liable to necessary and proportional harms to avert these threats. Such a view rejects the claim that the criterion of liability is responsible for unjust threats. Still, even if one subscribes to such a view, one may hold that what counts as proportional defensive harm partly depends on how responsible the threatening agent is, i.e. even an advocate of a Causal Account of Liability can subscribe to the Responsibility-Sensitive Account of Proportionality. Therefore, this latter account does not presuppose the Responsibility Account of Liability.

The Responsibility-Sensitive Account of Proportionality explains why Bob is liable to be killed in the Abusive Boyfriend Scenario, but the non-liable Caroline, while equally threatening, should be left alive. Bob is clearly liable to the full extent of defensive harm that may befall on him in response to threats he poses. But why is he liable to harms that set back his vital interests, i.e. killing, while he only poses threats to Abigail's non-vital interests? The Responsibility-Sensitive Account of Proportionality explains this. Bob is responsible for creating an environment in which most of Abigail's non-vital interests are set back, thus posing a serious, though non-vital threat to her. On the Responsibility-Sensitive Account of Proportionality, the fact of responsibility renders the proportionality requirement looser and allows Abigail to inflict greater harms on Bob than the ones with which he threatens, including killing him. Note that the explanation works in tandem with Frowe's Aggregation Account: Bob's threats to Abigail's non-vital interests aggregate so that they are just short of a vital threat. But by themselves, these threats can never reach that threshold. If they could, then Caroline could be permissibly killed, but this is not the case. The reason why Abigail may inflict harms above the said threshold is that the responsibility on Bob's part loosens the proportionality requirement, and since Bob's threats are aggregated to be just short of a vital threat, looser proportionality now permits lethal defensive response.

How is all this relevant to revolution against Stably Non-violent Oppressive Regimes? In my view, the Abusive Boyfriend Scenario is analogous in important ways to stably non-violent oppression. In both cases only individuals' non-vital interests are threatened, and all paths to non-violent regime change are blocked; the only way out is by applying lethal force. One may object that the types of interests threatened by non-violent oppressors and by Bob are very different. The interests set back by the abuser are interests in leading a full social life, in pursuing gainful employment in accord with one's preferences, in short, in living one's life on one's own terms. On the other hand, citizens in a Stably Non-violent Oppressive Regime are deprived mainly of their political rights. While no one denies the importance of being able to exercise one's right to free speech or free assembly, these rights hardly seem to be on a par with being able to socialize with people of one's own choosing. Even if Abigail's situation falls short of enslavement or imprisonment, it appears to be significantly worse than living in a Stably Non-violent Oppressive Regime.

How could this objection be answered? First, the importance of political rights should not be downplayed. Having one's right to freely speak one's mind, freely associate with others and live under a government elected by and accountable to oneself are centrally important to living a dignified life in human society. Even those 
who dislike the idea of armed revolution in defence of political rights usually recognize that peaceful struggles for these rights aim at bringing about results which are fundamentally valuable. Still, simply positing that political rights, similarly to Abigail's non-vital interests, are worth killing for, would make a poor argument for my thesis, as it would merely stipulate what needs to be proven.

A more substantive argument to this effect is as follows: the claim that there is a discontinuity between non-political and political interests is false. It is wrong to think that Abigail in the Abusive Boyfriend Scenario faces harsher threats than citizens in a Stably Non-violent Oppressive Regime. It is true that having to suffer a setback to our interests in freely pursuing a social life or work is worse than being subjected to censorship or not being able to run for office in national elections. But when a wide-enough array of our political rights is violated, this usually has ripple effects on our non-political interests as well. Abigail is constrained in her choosing a workplace for herself. So too is a person living under a Stably Non-violent Oppressive Regime whose ability to choose an occupation depends on a labour law, contract law, revenue law, legislated by a body unelected by and unaccountable to the people over whom it rules.

Political institutions set the stage in which we pursue our non-political interests in society. Whether I can socialize with my friends depends on whether there are places we can gather and engage in the kind of activities through which we would like to cultivate our friendship and have fun together. But this depends on what is legal and what is not; whether the clubs, cafés, cinemas we like can comply with the government's regulations, can afford the taxes and so on. For this reason, I believe that the Abusive Boyfriend Scenario and the case of Stably Non-violent Oppressive Regimes are analogous in important ways. In both cases we can talk of deliberate setbacks to an extremely wide array of individuals' non-vital interests, and only these, with all paths to peacefully averting these threats non-violently blocked. If so, both kinds of threats merit the same response, namely defensive killing which in the case of stably non-violent regimes could mean revolution.

To reiterate, while Stably Non-violent Oppressive Regimes do not threaten citizens' vital interests, they deliberately create a situation in which most of citizens' fundamentally important political rights are not protected and cannot be exercised. The fact of responsibility on the part of the oppressors loosens the proportionality requirement that needs to be invoked in evaluating their liability to defensive harm. As the Abusive Boyfriend Scenario shows, if the threats to non-vital interests are extensive enough, then the loosened proportionality requirement may render threatening agents, i.e. stably non-violent oppressors in this case, liable to defensive killing. And since revolution was defined in 'Revolution as Defence Against Oppression' section as defence against oppression, we can conclude that Stably Non-violent Oppressive Regimes can be liable to revolutionary attack.

Note that this does not imply that all Stably Non-violent Oppressive Regimes are liable to revolutionary attack. Numerous further circumstances need to be taken into consideration. For example, the oppressive regime's threats to citizens' political rights need to be aggregated into a serious enough threat. Possibly no state protects all of its citizens' political rights perfectly, and, clearly, leaving a single political right unprotected would not render a government liable to revolutionary attack. 
Furthermore, stably non-violent oppressors have to be responsible in the relevant sense in order for the Responsibility-Sensitive Account of Proportionality to apply. As we will see in the following section, this raises very important problems. Furthermore, even if a Non-violent Oppressive Regime is liable to revolutionary attack, this does not necessarily mean that revolution against that regime is justified. Again, the overall justifiability of revolution depends on the probability of success, the harms potentially inflicted on non-revolutionary citizens and other parties and many other criteria in addition to liability.

Still, this account of revolution in defence of political rights appears plausible. It achieves its purpose, i.e. shows that under some circumstances a government can be liable to revolutionary attack for non-violent oppression. At the same time, the account is not committed to the implausible view that there is a general right to kill for liberty. It also allows us not to 'take lightly the idea that policemen and women, public officials or soldiers in an oppressive state can simply be killed without wronging them regardless of other circumstances' (Finlay 2015, p. 58). Some police officers and public officials are similar to Caroline in the Abusive Boyfriend Scenario, themselves merely victims of oppression. Some, however, having access to an adequate range of other options will have voluntarily signed up for contributing to the non-violent oppression of their fellow citizens, perhaps only to further their careers or to have access to opportunities most people in their country do not. These latter individuals will be morally analogous to Bob, and therefore may be liable to revolutionary attack.

\section{Dilemmas of Responsibility}

One may doubt that the Responsibility-Sensitive Account of Proportionality in fact provides the best way to explain why Stably Non-violent Oppressive Regimes are liable to revolutionary attack. It implies that if non-violent oppressors lack responsibility for threatening a wide enough range of citizens' non-vital interests, then they are not liable to revolutionary attack. This appears to be counterintuitive. Suppose that you live in state led by a dictator who suffers from some kind of mental illness in virtue of which she cannot be thought of as responsible for her actions. History provides plenty examples of political leaders with mental health problems. But this dictator, being something like a very calm version of Nero, refrains from the widescale murder or torture of citizens. Her mild sadistic tendencies only compel her to establish a Stably Non-violent Oppressive Regime of the kind we have previously discussed. If her mental illness is severe enough so that she cannot be thought of as responsible, do her subjects have to suffer oppression and abstain from revolution?

In reality such a case would hardly present a problem. Unless all of the dictator's staff—all the generals, police officers, censors, and so on-equally lack responsibility, revolutionary action may still be justified. It does not seem far-fetched to say that once all the proper agents of oppression have been defeated, perhaps in bloody battles, and the dictator is found in her office consumed by her mental illness, the revolutionaries should send her to a medical facility rather than to the execution squad. Still, the challenge of non-responsible oppressors to the Responsibility-Sensitive 
Account of Proportionality is serious. The account holds that revolutionary attack is only proportional insofar as individual oppressors - from the prime minister through police officers to public officials-are responsible for the threats they pose to the non-vital interests of citizens. But individual police officers and public officials may fail to have a sufficient level of responsibility. They may be kept non-culpably ignorant of the workings of the regime which may reduce their responsibility or even excuse them (Lepora and Goodin 2013, p. 96; see also Isaacs 2011, Chapter 6; Kutz 2000, p. 157); their contribution to oppression may be so sporadic, unsystematic and insignificant, and oppressive practices so decentralized that responsibility can only be attributed to the whole of the oppressive system, but not to low-level agents of oppression (see Thompson 1980; Copp 2007; Pettit 2007). If so, then the Responsibility-Sensitive Account of Proportionality prescribes that prospective revolutionaries refrain from attack condemning them to oppression. ${ }^{6}$

In light of this, should we not opt for a theory that allows revolutionary action even in the case of minimally responsible non-violent oppressors, or alternatively abandon the idea of revolution against non-violent oppression altogether? One argument for the former may be derived from the Abusive Boyfriend Scenario. Suppose that Bob himself is mentally ill or is drugged or otherwise coerced into acting the way he does. It seems strange to say that Abigail is now morally required to submit to her oppression, and she is now without morally justifiable options to resist. This leads us back to the hypothesis that Bob and non-violent oppressors in general, for all intents and purposes, can be treated as threatening vital interests. As noted earlier, this has the unwelcome consequence that Caroline, Bob's innocent helper, herself coerced into assisting with Abigail's oppression, may be permissibly killed by Abigail. Indeed, if Bob lacks responsibility he is more or less on a par with Caroline from the moral point of view; whatever applies to him should apply to her and vice versa.

However, this, in my view, provides a good reason for making peace with the prohibition of killing minimally responsible non-violent oppressors. If the rejection of the prohibition implies the permissibility of using lethal force against innocent threats to non-vital interests, e.g. killing Caroline, then we should choose the prohibition. Abigail's freedom is of great importance, but our priority should always be protecting the innocent. Oppression may justify tyrannicide, i.e. the killing of the oppressors, but as Finlay noted, it is not a licence to kill without moral consequences. If there is no tyrant, no individual or group responsible for the oppression to be found, we may not kill whoever stands between us and our liberty. Equally oppressed and innocent subjects of oppression may not permissibly slaughter one another if this is the only way to freedom.

Note that the result is rather different in the case of non-responsible violent oppression which involves threats to individuals' vital interests. In those cases, even the Responsibility-Sensitive Account of Proportionality will permit lethal action. Under such circumstances non-responsible oppressors become innocent threats to

\footnotetext{
${ }^{6}$ We may take this to be a variation on Seth Lazar's (2010) responsibility dilemma to McMahan's Responsibility Account of Liability.
} 
our vital interests and as such can be permissibly killed even though they lack liability. Even if the whole cohort of oppressors is under the influence of some drug or mental illness, when they come to kill, torture and rape us, we have the right to defend ourselves with lethal force.

Still, it may seem untenable that in the absence of discernibly responsible oppressors victims of non-violent oppression are left without morally justifiable options to resistance. Carrying on with the analogy of the abusive boyfriend, should Abigail give up all her hopes to free herself if Bob's actions are due to some mental illness, drug or coercion? Answering this question in the positive, as the Responsibility-Sensitive Account of Proportionality would imply, may seem odd. However, I believe that it is possible to uphold the Responsibility-Sensitive Account of Proportionality while acknowledging that in some cases Abigail may kill Bob even if he is innocent. These are cases in which Abigail can impermissibly but excusably kill Bob. Suppose that Bob is a non-responsible non-violent oppressor, but Abigail is unaware of it. She has the justified false belief that she is in the standard Abusive Boyfriend Scenario, in which Bob is liable, and accordingly she proceeds to kill Bob. What should we make of this case?

Compare the following example: Smith draws a gun on Jones. Unbeknownst to Jones, Smith's gun is a low-power weapon that cannot inflict lethal harm on Jones, only a minor injury. Nonetheless, the gun looks like one that may kill Jones, thus he has the justified false belief that Smith poses a lethal threat to her. He responds accordingly and shoots Jones first. Jones was not liable to be killed in this scenario, nor was he a non-liable lethal threat whose killing in self-defence was justified. Smith should not have killed Jones, his action appears to be impermissible. Once he learns about his mistake, he acquires good reasons to feel deep regret, and may even have duties of paying reparation to Jones's family, and so on. Nonetheless, it is not hard to see why his actions may be excused. Smith thought, mistakenly, that he was in mortal danger. Similarly, in the case above, we might believe that Abigail impermissibly but excusably killed Bob who, while he did innocently threaten her, did not pose a grave enough threat to warrant a lethal defensive response.

When it comes to revolutionaries in a non-violently oppressive regime, we may face a similar situation. Discerning which agents are sufficiently responsible for partaking in oppression, and are therefore appropriate targets of revolutionary attack, may be incredibly challenging. A great deal of epistemic uncertainty is involved in any kind of irregular armed conflict. Even if revolutionaries have collected all the available information and deliberated carefully, they may still arrive at false conclusions about the level of liability of certain agents of oppression. For example, they may have the justified belief that only volunteers serve in a certain oppressive agency (e.g. the secret police or a branch of the military) and therefore attack them as responsible agents of non-violent oppression. Such agents would indeed be liable to revolutionary attack according to the Responsibility-Sensitive Account of Proportionality. But suppose that later the revolutionaries find out that these agents were in fact coerced into collaboration and were themselves victims of oppression. Upon this revelation they should come to the conclusion that said agents were not in fact appropriate targets of revolutionary attack. This may constitute grounds for reconciliation, public apologies, reparations for the families of the killed and so on. In such 
a case, revolutionaries act in an impermissible, but excusable manner. However, if no such revelation occurs, i.e. if said individuals were indeed responsible agents of non-violent oppression, and therefore liable to revolutionary attack, then no such reconciliatory measures are in order.

But what if Abigail knows that Bob is not responsible for oppressing her? What if revolutionaries are fully aware that there are no discernibly responsible agents of oppression in society? Should then they refrain from action? To many, such a conclusion might seem unacceptable. It implies that if Stably Non-violent Oppressive Regimes spread responsibility 'thinly' enough in the population so that all agents of oppression are at best innocent threats to non-vital interests, and no single person is responsible enough to be liable to be killed, then revolutionaries may end up being morally required to submit to their non-violent oppression regardless of how extensive it is. This is not an account of revolution, but a recipe for oppressors to avoid liability. One intuition that drives this discussion is that oppressors should not be able to restrict citizens' options to self-defence simply by choosing softer forms of oppression.

I believe that the worry is genuine. I also think that in the case of victims of oppression, whether violent or non-violent, we should be extremely understanding of their desperation, fear and the uncertainties among which they live. And we should assign great weight not only to their vital interests, but also to their interests in living as citizens of a free state, capable of exercising their political rights, and under a legitimate government that works for, rather than against them. Still, we need to take seriously the question of how these non-vital interests should be weighed against innocent oppressors' vital interest in life and security. Should the latter suffer death at the hand of their fellow victims of oppression, simply because they had the misfortune of being coerced into upholding oppression in addition to being subjected to it? I believe our answer should be a firm 'no'. Liberty is precious enough to kill, if necessary, those who are taking it away, but not nearly valuable enough to dispense with innocent lives in its defence.

\section{Conclusion}

Today we witness the rise of new paradigms of oppression. As technological development enables oppressors to monitor and manipulate citizens more effectively than ever, they can become less reliant on violent oppression and fear. In a more and more interconnected world in which fewer and fewer countries can afford pulling out of global markets and international treaties completely, autocrats may have an incentive to opt for less overt and less saliently violent forms of oppression to avoid severing ties with the international community. Non-violent oppression may blend into the background of everyday life more easily, depriving citizens from their political rights in a more insidious, yet just as effective way. Theories of resistance in general, and those of revolutionary action in particular, need to be able to address the problem of non-violent oppression, that is, to clarify under what circumstances people may take up arms to defend themselves in the absence of overt state violence. This paper contributed to this task by 
establishing the liability of some Stably Non-violent Oppressive Regimes to revolutionary attack based on the Responsibility-Sensitive Account of Proportionality.

Acknowledgements Open access funding provided by Central European University.

Open Access This article is distributed under the terms of the Creative Commons Attribution 4.0 International License (http://creativecommons.org/licenses/by/4.0/), which permits unrestricted use, distribution, and reproduction in any medium, provided you give appropriate credit to the original author(s) and the source, provide a link to the Creative Commons license, and indicate if changes were made.

\section{References}

Buchanan, Allen. 2013. The ethics of revolution and its implications for the ethics of intervention. Philosophy \& Public Affairs 41: 291-323.

Buchanan, Allen. 2016. Self-determination, revolution, and intervention. Ethics 126: 447-473.

Chen, Jidong, and Yiqing Xu. 2017. Information manipulation and reform in authoritarian regimes. Political Science Research and Methods 5: 163-178.

Copp, David. 2007. The collective moral autonomy thesis. Journal of Social Philosophy 38: 369-388.

Draper, Kai. 2009. Defense. Philosophical Studies 145: 69-88.

Finlay, Christopher J. 2015. Terrorism and the right to resist: A theory of just revolutionary war. Cambridge: Cambridge University Press.

Frowe, Helen. 2014. Defensive killing. Oxford: Oxford University Press.

Guriev, Sergei M., and Daniel Treisman. 2018. Informational autocracy: Theory and empirics of modern authoritarianism. https://ssrn.com/abstract=2571905. Accessed June 18, 2019.

Isaacs, Tracy. 2011. Moral responsibility in collective contexts. Oxford: Oxford University Press.

Iser, Mattias. 2017. Beyond the paradigm of self-defense? On revolutionary violence. In The ethics of war: Essays, ed. Saba Bazargan and Samuel C. Rickless, 208-227. Oxford: Oxford University Press.

Kutz, Christopher. 2000. Complicity: Ethics and law for a collective age. Cambridge: Cambridge University Press.

Lazar, Seth. 2009. Responsibility, risk, and killing in self-defense. Ethics 119: 699-728.

Lazar, Seth. 2010. The responsibility dilemma for killing in war: A review essay. Philosophy \& Public Affairs 38: $180-213$.

Lazar, Seth. 2014. National defence, self-defence, and the problem of political aggression. In The morality of defensive war, ed. Seth Lazar and Cécile Fabre, 12-39. Oxford: Oxford University Press.

Lepora, Chiara, and Robert E. Goodin. 2013. On complicity and compromise. Oxford: Oxford University Press.

Locke, John. 1982. Second treatise of government, ed. Richard H. Cox. Wheeling, IL: Harlan Davidson.

McMahan, Jeff. 1994. Self-defense and the problem of the innocent attacker. Ethics 104: 252-290.

McMahan, Jeff. 2005. The basis of moral liability to defensive killing. Philosophical Issues 15: 386-405.

McMahan, Jeff. 2009. Killing in war. Oxford: Oxford University Press.

Norman, Richard. 1995. Ethics, killing and war. Cambridge: Cambridge University Press.

Otsuka, Michael. 1994. Killing the innocent in self-defense. Philosophy \& Public Affairs 23: 74-94.

Parry, Jonathan. 2018. Civil war and revolution. In The Oxford handbook of ethics of war, ed. Seth Lazar and Helen Frowe, 316-332. Oxford: Oxford University Press.

Pettit, Philip. 2007. Responsibility incorporated. Ethics 117: 171-201.

Pitts, Chip, and Anastasia Ovsuannikova. 2015. Treason statute, anti-NGO and other repressive laws: Sovereign democracy or renewed autocracy. Huston Journal of International Law 37: 83-138.

Quong, Jonathan. 2009. Killing in self-defense. Ethics 119: 507-537.

Quong, Jonathan. 2012. Liability to defensive harm. Philosophy \& Public Affairs 40: 45-77.

Quong, Jonathan. 2015. Proportionality, liability, and defensive harm. Philosophy \& Public Affairs 43: 144-173.

Rodin, David. 2002. War and self-defense. Oxford: Oxford University Press.

Rodin, David. 2014. The myth of national self-defence. In The morality of defensive war, ed. Cécile Fabre and Seth Lazar, 70-90. Oxford: Oxford University Press.

Smith, Matthew Noah. 2008. Rethinking sovereignty, rethinking revolution. Philosophy \& Public Affairs 36: $405-440$. 
Thomson, Judith Jarvis. 1991. Self-defense. Philosophy \& Public Affairs 20: 283-310.

Thompson, Dennis F. 1980. Moral responsibility of public officials: The problem of many hands. The American Political Science Review 74: 905-916.

Varol, Ozan O. 2015. Stealth authoritarianism. Iowa Law Review 100: 1673-1742.

Publisher's Note Springer Nature remains neutral with regard to jurisdictional claims in published maps and institutional affiliations. 